\title{
The Role Of Positive Regard In Self-Regulated Learning: An Analysis Of Student Evaluation Data
}

Joseph T. Harder, Indiana State University, USA Ayman H. Abuhamdieh, Indiana State University, USA

\begin{abstract}
Learning outcomes in classroom settings are impacted by many components of the course structure and delivery. One of these is positive regard from the instructor as perceived by students. Similarly, perceived positive regard is an important aspect of learning outcomes in a distance education environment, although the ways in which regard are shown are much different. The present study seeks to quantify the impact of perceived positive regard on learning outcomes in both classroom and distance modalities and compare the results for similarities and differences. Data from the Student Instructional Report, both classroom and distance versions, from the authors' institution is used to validate the relationships among positive regard, motivation, and learning outcomes shown in Eflides's (2011) metacognitive and affective model of self-regulated learning (MASRL). Analysis of data from one academic year of available data does support these relationships, with some differences found between distance and traditional classroom settings. Support and suggested direction for future research on the role of positive regard in distance learning are offered.
\end{abstract}

Keywords: Positive Regard; Affective Model; Self-Regulated Learning; Learning Outcomes; Distance Education

\section{INTRODUCTION}

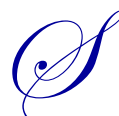

tudent-instructor communication and interactivity is crucial in the educational process, especially as the Web has become an important platform for online education delivery (Croxton, 2014). Many students attend classes that are either completely online, or are meeting in blended format of face-to-face and online using different technologies, such as Blackboard, WebCT, Moodle, and many others. When students and instructors meet face-to-face, it is easy to communicate non-verbal cues that frame the conversation. A nod, a smile, physical proximity, the voice tone, or a myriad of facial expressions can convey many non-verbal cues that are usually part of face-to-face communication.

When communicating online, these non-verbal cues are absent, which creates challenges for building rapport and could lead to miscommunication (Huang \& Hsiao, 2012; Kathleen \& Thomas, 2006; Michael \& Earlie, 2000). Students are much more independent in the online class environment, and they need to rely more on themselves to manage or regulate their learning to achieve the educational goals they have set for themselves (Efklides, 2011, 2014). Students bring many traits, affect, skills, abilities and knowledge when they join classes. These factors interact within students' cognition while they are engaging in the learning process.

While the role of emotions and affect in education has been examined in many earlier studies (ClevelandInnes \& Campbell, 2012; Kathleen \& Thomas, 2006; Michael \& Earlie, 2000; Milheim, 2012), its role in distance education did not receive much emphasis, despite its link to positive student outcomes (Papantoniou \& Plakitsi, 2012). Specifically, the role and influence of positive regard on student outcomes. 
Positive regard is a concept that refers to the positive exhibition of emotions from the instructor to the students within the educational environment (Aspy \& Hutson, 1972). It has been shown to impart positive influence on students in the traditional, face-to-face settings (Aspy \& Roebuck, 1972; Papantoniou \& Plakitsi, 2012), however, that influence and link has not been examined in the online or distance education setting.

The concept of positive regard in distance education came to light by the leading author who taught a class to less advantaged or 'troubled' students. Many of these students could not fit into the traditional school learning environment and had to take these special classes. When the instructor showed positive regard towards the students, the student responded positively by showing better learning outcomes results. The class was in a face-to-face setting, so the question that arose was how could this kind of positive regard be exhibited in an online class?

This study aims to shed more light on this important aspect of positive regard in the distance or online educational process and examine its relation to student learning outcomes.

\section{LITERATURE REVIEW}

Student emotions are identified as an integral part of the educational environment. Students and instructors express themselves in different facets regardless of the communication medium, synchronous/face-to-face, asynchronous/distance/online, or hybrid/blended (Cleveland-Innes \& Campbell, 2012).

Students and instructors communicating in online classes use electronic means, such as email, discussion boards, blogs, and other media. Expressing emotions and establishing rapport between students and instructors and students with other students is challenging (James, Scott, \& Michael, 2009; Kathleen \& Thomas, 2006; Michael \& Earlie, 2000).

Croxton (2014) points in a literature review study on the role of interactivity between students and instructors in student satisfaction in distance education to the importance of this interactivity. Depending on the learner type, interactivity was found to be an important factor in online student class experience (Croxton, 2014). The study calls for empirical examination of the role of interactivity on student online course experience satisfaction.

Communication between students and instructors was found to be the most critical factor in good quality online distance education courses. More specifically, instructor feedback and online communication tools such as email, discussion groups and chat rooms were found to be of most value (Ortiz-Rodríguez, Telg, Irani, Roberts, \& Rhoades, 2005).

Emotional expression in online classes is more challenging to convey and could lead to misinterpretations and miscommunication. Milheim (2012) examined student needs in online classes through Maslow's Hierarchy. The relationship or belonging and self-esteem needs in the hierarchy are more difficult to attain in this setting because of the nature of the online classes. Students and instructors do not meet in person; thus the immediate feedback available in face-to-face settings is absent in the online environment. This could be mitigated by using online communication tools such as email, discussion forums and fast feedback on assignments (Milheim, 2012).

In a comparative study of synchronous or face-to-face vs asynchronous or online classes, (Huang \& Hsiao, 2012) report that online classes, while viewed as fun and involved a lot of work, it was also a ground for miscommunication due to the absence of visual expressions, such as body and facial languages. Additionally, students and faculty felt disconnected, in the sense of having a personal connection that is felt in the synchronous form of communication.

SWOT (strength, weakness, opportunity, threat) analysis was used to analyze student perspectives about blended class quality and its delivery. Many weaknesses were cited by students more than strengths, such as less human interaction with the professor, which could lead to miscommunication, less learning quality in the distance component of the class, and less interaction with other students (Jackson \& Helms, 2008). 
Studies suggest different practices, mechanisms and tools to mitigate the negative aspects of communicating online, such as messages sent by faculty that are respectful, positive, timely, and supportive in addition to prompt feedback (Plante \& Asselin, 2014) and the effective use of online communication tools such as email and discussion boards (Kathleen \& Thomas, 2006).

Online classes require higher level of student independence and self-regulation than face-to-face classes. Schunk \& Zimmerman (1994) define self-regulated learning (SRL) as "the process whereby students activate and sustain cognitions, behaviors, and affects, which are systematically oriented toward attainment of their goals" (p. 309). This definition stresses the process of setting forth goals that students aim to achieve and put the personal resources needed to attain these goals, namely: cognition, behavior, and their emotion or affect. Students come to the learning environment along with their emotions and personality and have certain expectations from the instructor they are interacting with (Schunk \& Zimmerman, 1994).

Affect is viewed as an integral component of self-regulated learning, or SRL, along with metacognition and motivation. These variables and their interactions are linked in the Metacognitive and Affective Self-Regulated Learning (MASRL) model (Efklides, 2011). Affect, as it interacts with the other model components, influences the task or the outcome planned or expected to be accomplished. The MASRL model is composed of cognition, metacognition, affect, and volition. Affect refers to the attitudinal and emotional parts of a learning subject or person. It's inclusion in the MASRL model is consistent with, and acknowledges in its construction, Bandura's (1986) construct of self-efficacy. It is defined as academic emotions in the model and it is assumed to be independent of metacognitive knowledge, however it is related to motivation.

A student's self-concept in the knowledge area and the perception of the task's level of the difficulty governed by earlier knowledge of that task influence the expected learning outcome. Affect emerges from positive attitudes towards that task, and is formed at the person level as opposed to the (task x person) level in the model. Self-regulated learning and positive affect were found to be related to course outcomes, and is influenced by personality traits, which supports the MASRL model (Papantoniou \& Plakitsi, 2012).

Several comparative studies between online and face-to-face settings were conducted with results that emphasize the importance of communication, the possibility of miscommunication and the difficulty in establishing rapport between the instructor and the students (Al-Saleh, 2002; Aspy \& Roebuck, 1972; Hale, Mirakian, \& Day, 2009; Hannay \& Newvine, 2006).

(Aspy \& Hutson, 1972) used the concept of positive regard to compare two groups of teachers who rated high and low on promoting student success. Teachers who used more praise than criticism, developed student ideas, were sincere in their responses to students and showed positive regard for the students as persons were rated high on promoting student success compared to the other teacher group. In another study, (Aspy \& Roebuck, 1972) found a significant relationship between positive regard and higher level of student cognitive functioning. These early studies were conducted long before online education was developed.

In a comparative study about the difference between distance and face-to-face courses on the BarrettLennard Relationship Inventory (BLRI) variables of perceptions of regard, unconditional regard, empathetic understanding, and congruence for registered nursing students revealed lack of difference between the two settings. Relationships between students and their instructors were comparable both online and in class (Al-Saleh, 2002).

Affect was not a factor in some studies that compared online vs. traditional classroom teaching. Students reported many benefits and advantages to online courses, and achieved better learning outcomes such as attaining higher grades, reporting that they learned more, found the exams to be easier, spent more time studying for online classes, and perceived online classes as having higher quality (Hannay \& Newvine, 2006).

One of the features of face-to-face classroom instructions is rapport buildup that takes place as the class progresses. In an online setting where students do not physically interact with their instructor and do not see any feedback cues, such rapport is difficult to achieve. In an online vs. classroom instruction study in an allied health class, two groups of students were compared on several variables, such as satisfaction, rapport with the instructor, 
peer interaction, and self-perceived knowledge gains, researchers found that students in the online course were less satisfied with all of the aforementioned variables, although student educational outcomes were the same for both groups (Hale et al., 2009).

In some instances, student age plays a role in determining whether affect is in important factor in student online experience satisfaction. Mature students in graduate programs in higher education institutions do not emphasize instructor empathy, positive regard or affect, immediate feedback from the instructor on messages or assignment, rather the importance is put on constructive critical feedback on assignments, and instructor enthusiasm for helping students (Alison, 2004).

\section{RESEARCH MODEL}

A causal relationship between empathy/positive affect shown by instructors toward students, and quality of learning outcomes is supported by the foregoing literature review. The authors will build on a model published by Efklides (2011) to structure several research questions and establish a methodology to test them.

The MASRL model expands on (Bandura, 1989) notion that affective state impacts performance on learning tasks through improving self-efficacy (self-concept relative to a particular task). In the MASRL model, affect impacts motivation at the person level in two ways. First, there is a direct impact on motivation. Positive affect impacts motivation in an immediate fashion due to an improved emotional state. Secondly, affect impacts motivation indirectly by way of self-concept. The more positive one's self-concept, the more confident he/she will be that effort put into learning will be rewarded.

For purposes of the current study, only the upper portion (Person Level) of the MASRL model (Figure 1) is tested. Specifically, the authors are keenly interested in quantifying the impact of affect on student motivation and self-reported learning outcomes. The links between affect and motivation have been discussed above, and the expected link between affect and eventual learning outcomes is supported in the literature review (Cleveland-Innes \& Campbell, 2012) as well as the eventual link to performance in the MASRL model (by way of enhanced Metacognitive Skill and Metacognitive Knowledge).

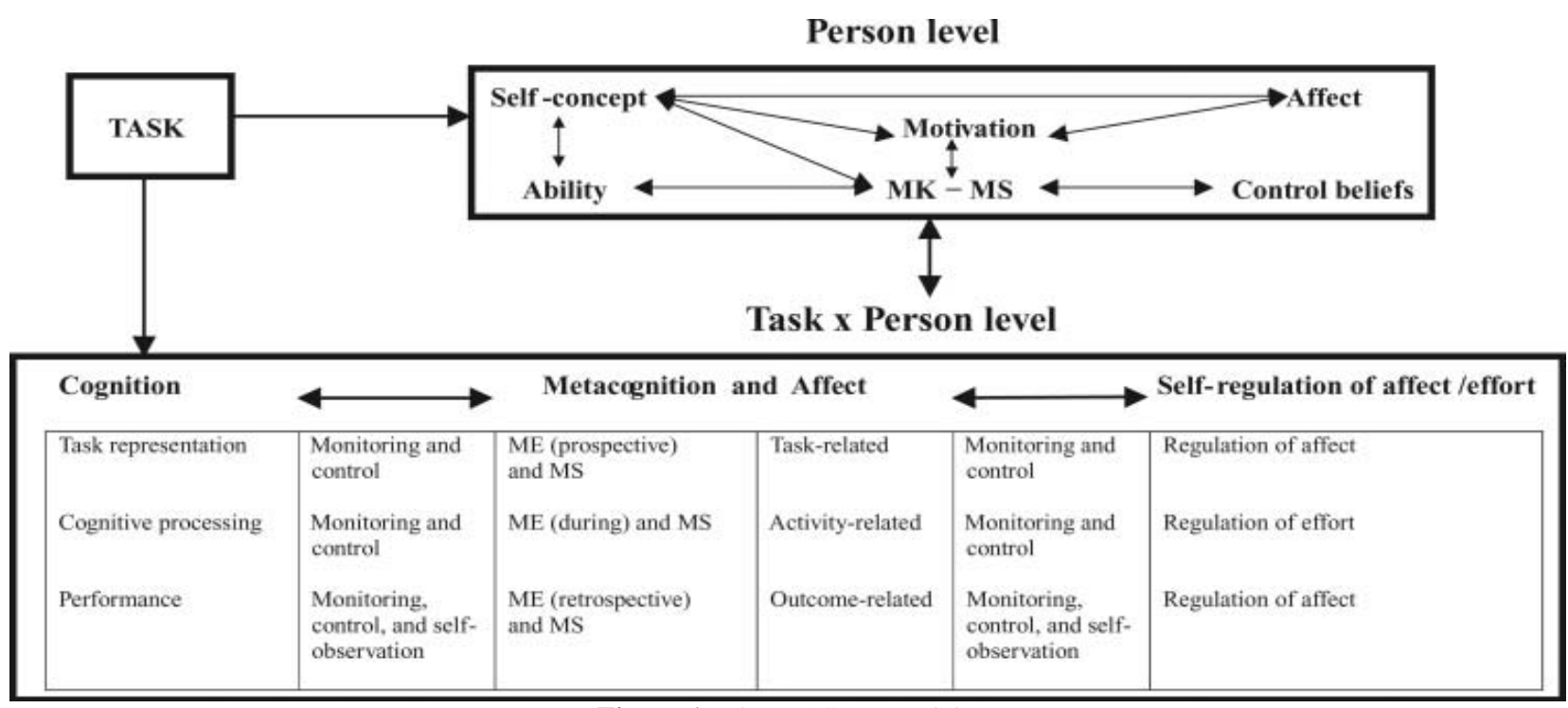

Figure 1: The MASRL Model

In order to synthesize the various studies cited in the literature review investigating the role of an emotional connection between learner and student, the authors will use the term "Perceived Positive Regard" in our research questions. It will be a proxy for the term 'affect' in the MASRL model. Perceived Positive Regard is posited as a positive emotional state, or positive affect felt by the learner (emphasis added). 
Since the author's institution has used the Student Instructional Report (SIR II and eSIR) instruments from Educational Testing Service (ETS) for a number of years, individual response data is available. Data were available both from traditional (SIR II) and distance learning (eSIR) sections. Details of the dataset and procedures used will be discussed in the next section.

Both the SIR II and eSIR instruments contain questions regarding instructor behaviors along several dimensions, self-reported learning outcomes, and efforts expended by the students toward achieving those learning outcomes. While the complete instruments cannot be reproduced in the context of publishing this study, the dimensions measured and the number of questions along each dimension can be reported, and are presented below in Table 1, along with a brief characterization of the actual questions.

Table 1: Question Categories Within The SIR II And eSIR Instruments

\begin{tabular}{|c|c|c|c|}
\hline Dimension & Number of Questions & Characterization of Questions & Question Scaling \\
\hline Course Organization and Planning & 5 & Is the course well organized? & $1=$ Worst, $5=$ Best \\
\hline Communication & $\begin{array}{l}5-\text { SIR II } \\
6-\mathrm{eSIR} \\
\end{array}$ & Does the instructor communicate effectively? & $1=$ Worst, $5=$ Best \\
\hline Faculty/Student Interaction & 5 & Does the instructor care about me? & $1=$ Least, $5=$ Most \\
\hline Course Outcomes & 5 & Do I feel that I learned something? & $1=$ Worst, $5=$ Best \\
\hline Student Effort and Involvement & 3 & Did I expend a lot of effort toward learning? & $1=$ Least, $5=$ Most \\
\hline
\end{tabular}

Each section of questions will be aggregated into a composite score and given a variable name. These composite variables can then be investigated to determine whether positive relationships among them are supported. In addition, the raw, question-item level data is available for factor analysis. This will enable the authors to explore whether student's reported responses along these dimensions actually measure (factor load on) unique dimensions or whether they all simply measure a student's happiness with his/her class experience.

Each research question will be posed separately for classroom data (SIR II) and distance class data (eSIR). Any differences in outcomes will be discussed in the Results and Conclusions sections. Specific research questions (posed as affirmative hypotheses) are as follows:

H1a: Perceived Positive Regard in classroom settings is a unique factor, separate from other factors in the question set regarding instructor behavior

H1b: Perceived Positive Regard in distance settings is a unique factor, separate from other factors in the question set regarding instructor behavior

H2a: Perceived Positive Regard in classroom settings will be positively related to student reported learning outcomes

H2b: Perceived Positive Regard in distance settings will be positively related to student reported learning outcomes

H3a: Perceived Positive Regard in classroom settings will be positively related to student effort expended.

H3b: Perceived Positive Regard in distance settings will be positively related to student effort expended

\section{METHODOLOGY}

Data were obtained through a local Educational Testing Service (ETS) portal at the authors' institution. It was determined by the researchers that responses from the 2013/2014 Academic Year were sufficient to perform the planned analyses. Data came in four distinct sets, each in an Excel spreadsheet. Classroom (SIR II) and distance (eSIR) were available separately from both the fall and spring Student Instructional Response cycles.

Scrubbing and reformatting the data was performed with Microsoft Access. First, data were consolidated into two tables - one for SIR II data and one for eSIR data. Since the spreadsheets had many lines of embedded 
header data (above each class section reporting), they had to be removed. This was done with a delete query, deleting each line that did not have a complete data record. The resulting data sets yielded 3065 usable records with no missing fields for the eSIR and 7001 similarly clean data points for the SIR II. After scrubbing, data was exported back to Excel, since this is a file format easily imported into SPSS.

Final pre-processing and all data analysis was performed with IBM SPSS-19 (PC version). Before analytical procedures were performed, six composite variables were generated for each dataset. Many questions in the SIR II and eSIR were not included in the analyses. These questions either concerned students' opinions of textbooks and other non-instructor related aspects of the class, or were categorical in nature. Computed variables are summarized in Table 2.

In order to address hypotheses $\mathrm{H} 1 \mathrm{a}$ and $\mathrm{H} 2 \mathrm{a}$, principal components factor analysis was employed. All questions relating to instructor behavior were included in the factor analyses, along with student effort and expected outcomes. In addition, a generalized question about course quality (Q40 in the SIR II, and Q41 in the eSIR) was included to explore its factor loading. In both cases, a VARIMAX rotation was used to further highlight some factors that emerged during un-rotated factor analysis. The number of factors was not specified in any of the data runs.

Table 2: Computed Variables

\begin{tabular}{llc}
\hline Dimension from SIR II or eSIR Instrument & \multicolumn{1}{c}{ Transformation } & Variable Name \\
\hline Course Organization and Planning & Mean of questions 1 - 5 & ORGPLAN \\
\hline Communication & $\begin{array}{l}\text { Mean of questions 6-10 (SIR II) } \\
\text { Mean of questions 6-11 (eSIR) }\end{array}$ & COMM \\
\hline Faculty/Student Interaction & $\begin{array}{l}\text { Mean of questions 11-15 (SIR II) } \\
\text { Mean of questions 12-16 (SIR II) }\end{array}$ & REGARD \\
\hline Course Outcomes & $\begin{array}{l}\text { Mean of questions 29-33 (SIR II) } \\
\text { Mean of questions 30-34 (SIR II) }\end{array}$ & OUTCOME \\
\hline Student Effort and Involvement & $\begin{array}{l}\text { Mean of questions 34-36 (SIR II) } \\
\text { Mean of questions 35-37 (eSIR) }\end{array}$ & EFFORT \\
\hline
\end{tabular}

For Hypotheses H2a, H2b, H3a, and H3b, correlation matrices were run on each data set independently. Pearson correlations with two-tailed tests of significance were used. Output from all procedures will be transcribed into summary tables shown in the results section below.

\section{RESULTS}

In order to test Hypothesis H1a, following the procedures outlined in the preceding section, data from SIR II student responses (7001 records) were subjected to factor analysis independently. Output from the VARIMAX rotation is displayed in Table 3 below. For clarity, all factor loadings above .600 have been shaded. 
Table 3: Factor Loadings On Selected SIR II Questions

\begin{tabular}{cl|ccc}
\hline & & & Component & $\mathbf{3}$ \\
\hline Item & SIR II Section & $\mathbf{1}$ & .305 & .100 \\
\hline 1 & Course Org/Planning & .768 & .158 & .183 \\
2 & Course Org/Planning & .799 & .227 & .158 \\
3 & Course Org/Planning & .800 & .166 & .232 \\
4 & Course Org/Planning & .757 & .266 & .140 \\
5 & Course Org/Planning & .785 & .218 \\
6 & Communication & .790 & .072 & .137 \\
7 & Communication & .606 & .231 \\
8 & Communication & .776 & .257 \\
9 & Communication & .701 & .207 & -.008 \\
10 & Communication & .784 & .261 & -.014 \\
11 & Faculty-Student Interaction & .785 & .358 & -.022 \\
12 & Faculty-Student Interaction & .733 & .315 & .046 \\
13 & Faculty-Student Interaction & .704 & .386 & -.027 \\
14 & Faculty-Student Interaction & .660 & .321 & .320 \\
15 & Faculty-Student Interaction & .761 & .332 & .309 \\
29 & Course Outcomes & .386 & .724 & .239 \\
30 & Course Outcomes & .311 & .735 & .281 \\
31 & Course Outcomes & .311 & .767 & .246 \\
32 & Course Outcomes & .307 & .748 & .823 \\
33 & Course Outcomes & .344 & .736 & .734 \\
34 & Student Effort / Involvement & .092 & .297 & .786 \\
35 & Student Effort / Involvement & .119 & .171 & .450 \\
36 & Student Effort / Involvement & .094 & .631 & \\
40 & Overall Evaluation & & & \\
\hline
\end{tabular}

Similarly, student response data from eSIR student responses (3065 records) were subjected to principal components factor analysis, with output from the VARIMAX rotation displayed below. All factor loadings above .600 are shaded as above, with loadings between .500 and .599 shaded slightly lighter.

Table 4: Factor Loadings Of Selected eSIR Questions

\begin{tabular}{|c|c|c|c|c|c|}
\hline \multirow[b]{2}{*}{ Item } & \multirow[b]{2}{*}{ eSIR Section } & \multicolumn{4}{|c|}{ Component } \\
\hline & & 1 & 2 & 3 & 4 \\
\hline 1 & Course Org/Planning & .546 & .404 & .432 & -.056 \\
\hline 2 & Course Org/Planning & .638 & .360 & .317 & .040 \\
\hline 3 & Course Org/Planning & .757 & .195 & .219 & .080 \\
\hline 4 & Course Org/Planning & 639 & .303 & .380 & -.033 \\
\hline 5 & Course Org/Planning & .714 & .339 & .324 & .033 \\
\hline 6 & Communication & .763 & .158 & .118 & .141 \\
\hline 7 & Communication & .533 & .530 & .249 & .052 \\
\hline 8 & Communication & .745 & .321 & .180 & .119 \\
\hline 9 & Communication & .656 & .321 & .238 & .127 \\
\hline 10 & Communication & .633 & .412 & .171 & .092 \\
\hline 11 & Communication & .525 & .443 & .116 & .196 \\
\hline 12 & Faculty-Student Interaction & .378 & .748 & .262 & .039 \\
\hline 13 & Faculty-Student Interaction & .295 & .736 & .243 & .082 \\
\hline 14 & Faculty-Student Interaction & .292 & .740 & .217 & .081 \\
\hline 15 & Faculty-Student Interaction & .375 & .722 & .270 & .089 \\
\hline 16 & Faculty-Student Interaction & .331 & .721 & .179 & .139 \\
\hline 30 & Course Outcomes & .285 & .208 & .752 & .281 \\
\hline 31 & Course Outcomes & .239 & .170 & .755 & .258 \\
\hline 32 & Course Outcomes & .222 & .221 & .789 & .127 \\
\hline 33 & Course Outcomes & .184 & .229 & .751 & .228 \\
\hline 34 & Course Outcomes & .262 & .233 & .740 & .260 \\
\hline 35 & Student Effort / Involvement & .072 & .079 & .254 & .863 \\
\hline 36 & Student Effort / Involvement & .050 & .056 & .163 & .892 \\
\hline 37 & Student Effort / Involvement & .132 & .107 & .228 & .785 \\
\hline 41 & Overall Evaluation & .422 & .371 & .527 & .045 \\
\hline
\end{tabular}


To test the remaining hypotheses $(\mathrm{H} 2 \mathrm{a}, \mathrm{H} 2 \mathrm{~b}, \mathrm{H} 3 \mathrm{a}$, and $\mathrm{H} 3 \mathrm{~b})$ two separate correlation matrices were generated using Pearson bivariate correlation procedures implemented via IBM-SPSS v. 19. Inputs to the correlation matrices were all computed factors, as listed in Table 2. Output from the Correlation Matrix resulting from the SIR II data run is displayed in Table 5 below.

Table 5: Correlation Matrix For All Computed Variables Representing The SIR II Data

\begin{tabular}{lccccc}
\hline & ORGPLAN & COMM & REGARD & OUTCOME & EFFORT \\
\hline ORGPLAN & 1 & $.875^{* *}$ & $.785^{* *}$ & $.644^{* *}$ & $.323^{* *}$ \\
COMM & & 1 & $.794^{* *}$ & $.633^{* *}$ & $.323^{* *}$ \\
REGARD & & 1 & $.615^{* *}$ & $.277^{* *}$ \\
OUTCOME & & & & 1 & $.556^{* *}$ \\
EFFORT & & & & 1 \\
\hline
\end{tabular}

** significant at .001 level

Computed variables within the eSIR dataset were similarly analyzed. The resulting correlations are displayed in Table 6 below.

Table 6: Correlation Matrix For All Computed Variables Representing The eSIR Data

\begin{tabular}{lccccc}
\hline & ORGPLAN & COMM & REGARD & OUTCOME & EFFORT \\
\hline ORGPLAN & 1 & $.810^{* *}$ & $.741^{* *}$ & $.626^{* *}$ & $.253^{* *}$ \\
COMM & & 1 & $.767^{* *}$ & $.594^{* *}$ & $.291^{* *}$ \\
REGARD & & 1 & $.592^{* *}$ & $.279^{* *}$ \\
OUTCOME & & & & 1 & $.496^{* *}$ \\
EFFORT & & & & 1 \\
\hline
\end{tabular}

** significant at .001 level

\section{CONCLUSIONS AND IMPLICATIONS FOR FUTURE RESEARCH}

Regarding the first set of hypotheses (H1a and H1b), the authors' findings were mixed. From the SIR II data, which came from traditional classroom settings, response items which were used as a measure of positive regard did not factor load by themselves separately from questions measuring other instructor behaviors, such as organization, planning, and effective communication. All 15 questions did strongly load on a single factor, which the authors will interpret as students' general impression of instructor quality. Therefore, we must accept the null hypothesis that perceived positive regard is not, in itself, a unique factor in student evaluation of instructor performance. While it is possible that further rotations or different rotation techniques might have split these questions into separate factors, it was felt that the same exact procedures must be used with both data sets in order to fairly represent and compare results.

The other two factors aligned perfectly with the 'outcomes' and 'effort' related questions. This is certainly not a remarkable finding, since the instrument was designed and validated specifically by its authors to do just that. It is of interest, though, that Item 40 , which is in a section by itself designed to measure a student's overall evaluation of course effectiveness, loaded highly on the instructor behaviors factor, but only moderately on the outcomes factor.

Results from the eSIR data set are more promising. Items from the instrument measuring perceived positive regard did load strongly and uniformly on a separate factor from the other 11 questions regarding instructor quality. While 3 of these 11 questions did appear to straddle the two factors, every one of them loaded more heavily on the non- 'regard' factor. Based on this finding, the authors reject the null hypothesis for H1b. Positive regard, in the context of distance learning sections, is reported by students to be a separate dimension of their learning experience from other factors relating to instructor quality.

As in the prior factor analysis, 'outcomes' and 'effort' questions factor loaded quite highly and consistently together, confirming the instrument's validity in measuring these dimensions of students' experience with a class. In the eSIR, the single question measuring course effectiveness is item 41 , since there is an extra question in this version that comes in a prior section. This item loads moderately on three of the four factors, with 'outcomes' being the strongest of the three. In both analyses, the overall question did not load significantly on the 'effort' factor. 
For the remaining hypotheses, the authors will examine the correlation matrices, which display relationships among the five computed variables, used as measures of students' general perceptions about their class experience (refer to Table 2). Consistency with Efklides's (2011) MASRL model will be considered, along with the actual correlation coefficients. It should be noted that ALL correlations are significant at the .001 level due to the size of the datasets. Between the two correlation matrices, correlation coefficients between pairs of variables differ only slightly. Therefore, hypotheses H2a and H2b will be considered together. Similarly, H3a and H3b will be considered together.

In the MASRL model (Figure 1), 'affect', which the authors operationalize as perceived positive regard, impacts Metacognitive Skills and Metacognitive Knowledge which are both direct facilitators of task efficacy and performance. In our case, task performance is self-reported learning outcomes. Therefore, it is expected that perceived positive regard, (REGARD) will be positively correlated with learning outcomes (OUTCOME) in both classrooms (H2a) and distance (H2b) learning environments.

In Tables 5 and 6, correlation coefficients between REGARD and OUTCOME support a direct impact of perceived positive regard on expected learning outcome. For the classroom (SIR II) dataset, correlation was observed to be .615 , and in the distance dataset, the correlation was .592 . Therefore, the authors reject the null hypotheses that perceived positive regard does not directly impact learning outcomes, both in classrooms (H2a) and distance $(\mathrm{H} 2 \mathrm{~b})$ modalities. Interestingly, perceived positive regard was not the strongest of the observed correlations with learning outcomes. Organization and planning (ORGPLAN) and communication (COMM) were both slightly higher. While this finding does not diminish the significance of the impact of positive regard, it does indicate that there are other aspects of how the instructor conducts a class that are very important.

Lastly, since data was available to test the direct relationship shown in the MASRL model between affect and motivation (REGARD and EFFORT as we operationalize them) the authors did so. In both classrooms (H3a) and distance $(\mathrm{H} 3 \mathrm{~b})$ modalities, the relationship between these variables was significant, but significantly weaker than the relationships measured between REGARD and OUTCOME. In the case of classroom sections (SIR II), the observed correlation coefficient was .277, while in the distance sections (eSIR) it was .279.

As has been noted, due to the size of the datasets, all observed relationships are highly significant. Therefore, the null hypotheses that positive regard does not impact effort expended in classrooms (H3a) and distance (H3b) settings are rejected. While these findings do not dispute the relationships shown in the MASRL model, they do reflect on the strength of those relationships. A mitigating factor may be that items from the available dataset, and composite variables constructed therefrom do not comprise a perfect measure of 'motivation' as Efklides envisioned it.

In summary, the authors feel that these findings do support the importance of perceived positive regard in both classroom and distance settings. They support the many authors cited who believe strongly that a personal connection (stated many ways, such as 'empathy', 'rapport', 'regard', etc.) between instructor and student, regardless of setting is critical to positive learning outcomes. Some evidence was found (factor analyses) that perceived positive regard impacts students' experiences in distance sections in a slightly higher fashion than it does in traditional classroom setting. The connection between affect and motivation (REGARD and EFFORT in our study) shown in the MASRL model was supported.

Future investigation into the linkages between positive regard, motivation, and learning outcomes is needed for better understanding of the dynamics of learning in both classrooms and particularly distance modalities. While the authors used available data from the Student Instructional Report, questions on this instrument did not specifically target instructor behaviors in distance learning environments. A possible direction for future studies would be to develop scales for measuring demonstrated positive regard in distance settings using original, targeted questions.

The present study can support and guide such studies. The authors have shown that positive regard is strongly associated with perceived learning outcomes, possibly even more in distance settings that in traditional ones. This finding, coupled with the difficulty of expressing and perceiving positive regard in distance settings, emphasizes the need for further study, advancing best practice models in distance learning. 


\section{AUTHOR INFORMATION}

Joseph T. Harder is presently Associate Professor of Management Information Systems in the Scott College of Business at Indiana State University. He came to Indiana State in 1998 after obtaining a Ph.D. in Business Administration from Southern Illinois University. Other degrees held are a Bachelor of Arts in Psychology from Purdue and a Masters in Business Administration from Southern Illinois University. His research interests include assessing learning outcomes in the decision sciences and information systems pedagogy. He currently teaches undergraduate and graduate courses in Management Information Systems, specializing in Data and Knowledge Management. Email: Joe.Harder@indstate.edu.

Dr. Ayman Abuhamdieh obtained his master's and Ph.D. degrees from Rutgers University in 2001 majoring in management information systems and electronic commerce. His research interests include trust in electronic commerce, information systems pedagogy, online information search, and distance education. He teaches a wide variety of classes at both graduate and undergraduate levels in the Scott College of Business at Indiana State University. Email: ayman@indstate.edu.

\section{REFERENCES}

Al-Saleh, M. M. (2002). A description and comparison of RN-BSN nursing students' perceptions of student-teacher relationships in traditional and Internet distance education nursing courses. (D.N.Sc.), Widener University School of Nursing. Retrieved from https://ezproxy.indstate.edu/login?url=http://search.ebscohost.com/login.aspx?direct=true\&db=cin20\&AN $=2004051460 \&$ site $=$ ehost-live $\&$ scope $=$ site Available from EBSCOhost cin20 database.

Alison, S. (2004). "Off-campus support" in distance learning - how do our students define quality? Quality Assurance in Education, 12(1), 28-38.

Aspy, D. N., \& Hutson, B. (1972). Promotion of Student Success. The Journal of Educational Research, 66(2), 5761.

Aspy, D. N., \& Roebuck, F. N. (1972). An Investigation of the Relationship Between Student Levels of Cognitive Functionsing and the Teacher's Classroom Behavior. The Journal of Educational Research, 65(8), 365-368.

Bandura, A. (1989). Regulation of cognitive processes through perceived self-efficacy. Developmental Psychology, 25(5), 729-735. doi: 10.1037/0012-1649.25.5.729

Cleveland-Innes, M., \& Campbell, P. (2012). Emotional Presence, Learning, and the Online Learning Environment. International Review of Research in Open and Distance Learning, 13(4), 269-292.

Croxton, R. A. (2014). The Role of Interactivity in Student Satisfaction and Persistence in Online Learning. MERLOT Journal of ONline Learning and Teaching, 10(2), 314-324.

Efklides, A. (2011). Interactions of Metacognition with Motivation and Affect in Self-Regulated Learning: The MASRL Model. Educational Psychologist, 46(1), 6-25.

Efklides, A. (2014). How does metacognition contribute to the regulation of learning? An integrative approach. Psihologijske Teme, 23(1), 1-30.

Hale, L. S. P., Mirakian, E. A. M. P. A. P. A. C., \& Day, D. B. E. M. P. A. C. (2009). Online vs. Classroom Instruction: Student Satisfaction and Learning Outcomes in an Undergraduate Allied Health Pharmacology Course. Journal of Allied Health, 38(2), E36-42.

Hannay, M., \& Newvine, T. (2006). Perceptions of Distance Learning, a Comparison of Online and Traditional Learning. MERLOT Journal of ONline Learning and Teaching, 2(1), 1-11.

Huang, X. S., \& Hsiao, E. L. (2012). SYNCHRONOUS AND ASYNCHRONOUS COMMUNICATION IN AN ONLINE ENVIRONMENT: Faculty Experiences and Perceptions. Quarterly Review of Distance Education, 13(1), 15-30,49-50. doi: 10. Ill 1/j. 1083-6101. 1999.tb00098.x

Jackson, M. J., \& Helms, M. M. (2008). Student Perceptions of Hybrid Courses: Measuring and Interpreting Quality. Journal of Education for Business, 84(1), 7-12.

James, J., Scott, W., \& Michael, R. (2009). Increasing Student Discourse to Support Rapport Building in Web and Blended Courses Using a 3D Online Learning Environment. Journal of Interactive Learning Research, 20(3), 269-294.

Kathleen, W. P., \& Thomas, R. L. (2006). Graduate Distance Education in Family Relations: A Case Study. Family Relations, 55(1), 67-79. 
Michael, F., \& Earlie, W. (2000). A model for developing and managing distance education programs using interactive video technology. Journal of Social Work Education, 36(1), 147-147.

Milheim, K. L. (2012). Toward a Better Experience: Examining Student Needs in the Online Classroom through Maslow's Hierarchy of Needs Model. MERLOT Journal of ONline Learning and Teaching, 8(2), 159-171.

Ortiz-Rodríguez, M., Telg, R. W., Irani, T., Roberts, T. G., \& Rhoades, E. (2005). College Students' Perceptions of Quality in Distance Education: The Importance of Communication. The Quarterly Review of Distance Education, 6(2), 97-105.

Papantoniou, G., \& Plakitsi, K. (2012). Affect and Cognitive Interference: An Examination of Their Effect on SelfRegulated Learning. Education Research International, 2012, 1-11.

Plante, K., \& Asselin, M. E. (2014). Best Practices for Creating Social Presence and Caring Behaviors Online. Nursing Education Perspectives, 35(4), 219-223. doi: 10.5480/13-1094.1

Schunk, D. H., \& Zimmerman, B. J. (Eds.). (1994). Self-regulation in education: Retrospect and prospect. Hillsdale, NJ: Erlbaum. 
NOTES 